\title{
Effects of juvenile court exposure on crime in young adulthood
}

\author{
Amélie Petitclerc, ${ }^{1,2}$ Uberto Gatti, ${ }^{3}$ Frank Vitaro, ${ }^{4}$ and Richard E. Tremblay ${ }^{5}$ \\ ${ }^{1}$ National Center for Children and Families, Teachers College, Columbia University, New York, NY, USA; ${ }^{2}$ Geary \\ Institute, University College Dublin, Ireland; ${ }^{3}$ Department of Health Sciences, University of Genoa, Italy; ${ }^{4}$ Research \\ Unit on Children's Psychosocial Maladjustment, Universite de Montreal, Montreal, QC, Canada; ${ }^{5}$ School of Public \\ Health and Population Sciences, University College Dublin, Ireland, and Departments of Pediatrics, Psychiatry and \\ Psychology, Universite de Montreal, Montreal, QC, Canada
}

\begin{abstract}
Background: The juvenile justice system's interventions are expected to help reduce recidivism. However, previous studies suggest that official processing in juvenile court fails to reduce adolescents' criminal behavior in the following year. Longer term effects have not yet been investigated with a rigorous method. This study used propensity score matching to assess the impact of juvenile court processing into young adulthood. Method: Participants were part of a prospective longitudinal study of 1,037 boys from low- socioeconomic areas of Montreal, followed from ages 6-25 years. During their adolescence, 176 participants were processed in juvenile court, whereas 225 were arrested, but not sent to court. Propensity score matching was used to balance the group of participants exposed to juvenile court and the unexposed comparison group on 14 preadolescent child, family and peer characteristics. The two groups were compared on their official adult criminal outcomes. Results: The risk of conviction for an adult offence was $50.0 \%$ for court-processed participants compared with $24.3 \%$ for their matched counterparts, $\mathrm{OR}=3.13,95 \% \mathrm{CI}=1.80-5.44$. Court-processed participants committed an average of 0.39 violent crimes, compared with 0.15 for their matched counterparts; Poisson model IRR $=2.60$, $95 \% \mathrm{CI}=1.39-4.87$. They also committed an average of 2.38 nonviolent crimes, compared to 1.30 for their matched counterparts, IRR $=1.87,95 \% \mathrm{CI}=1.19-2.93$. Conclusions: Rather than decreasing recidivism, juvenile court intervention increased both violent and nonviolent future crimes. Along with previous studies, this study highlights a pressing need for more research and knowledge transfer about effective interventions to reduce recidivism among youths who commit crime. Keywords: Criminal behavior, violence, recidivism, penal justice, juvenile offenders.
\end{abstract}

\section{Introduction}

The health costs of crime account for $3 \%$ of medical expenses and $10-20 \%$ of mental health expenses in the United States (Miller, Cohen, \& Wiersema, 1996). As most repeat offenders first come into contact with the law as adolescents (Blokland, Nagin, \& Nieuwbeerta, 2005; Wiesner, Capaldi, \& Kim, 2007), the juvenile justice system may present an ultimate intervention opportunity to modify criminal behavior and reduce suffering. However, research suggests that it may instead increase reoffending, at least in the short term.

A recent Campbell Systematic Review included 29 experiments in which adolescents arrested by the police were randomly allocated to a diversion program or to usual court processing (Petrosino, Turpin-Petrosino, \& Guckenburg, 2010). All experiments were conducted in the United States except for two in Australia, and half focused on adolescents arrested for property, drug or status offences. Over the longest follow-up period, averaging 12-13 months across studies, the risk of reoffending and the frequency of offences was significantly

Conflict of interest statement: No conflicts of interests declared. higher for court-processed adolescents compared with those who were diverted, with or without services. Similarly, nonexperimental, matching studies of more diverse samples of offenders from different countries found no limiting effect of juvenile court processing, and in some cases found that it increased reoffending (Farrington, 1977; Huizinga, Schumann, Ehret, \& Elliott, 2004; McAra \& McVie, 2007). However, an important limitation of existing studies is that their follow-up periods were usually limited to 12 months and rarely included the adult years. This is a serious limitation to understanding the effects of the juvenile justice system, as the peak period of offending extends to the mid-twenties (Farrington, 1987; Hirschi \& Gottfredson, 1983; Sampson \& Laub, 2003). The present study addresses this limitation with a large communitybased sample of males from low-socioeconomic areas who were followed up to 25 years of age, hence covering the peak offending age period and providing much-needed empirical evidence about the effects of juvenile justice sanctions on individual criminal careers (DeLisi \& Piquero, 2011).

This study aimed to assess the effect of juvenile justice system processing under the Canadian Young Offenders' Act. We compared individuals brought to court as adolescents (ages 12-17) with 
individuals arrested during the same period, but not brought to court, on their official adult criminal behavior between ages 18 and 25. To address selection biases, we matched court-exposed participants to nonexposed participants with a similar propensity to be brought to juvenile court, on the basis of their preadolescent characteristics (Rosenbaum \& Rubin, 1984).

\section{Method \\ Participants}

The 401 participants whose data were used in this study came from an original sample of 1,037 boys recruited from schools located in low-socioeconomic areas of Montreal (Canada), in 1984. They had been invited to participate in the Montreal Longitudinal and Experimental Study (MLES), a study of the development of antisocial behavior in boys, starting in kindergarten, that included an intervention component for a small subsample ${ }^{1}$ (Gatti, Tremblay, \& Vitaro, 2009; Tremblay et al., 1991). Boys were included in the MLES if both their parents were Canadian-born, native French speakers with a maximum of 14 years of schooling. After the first data collection in the spring of the participants' kindergarten year, when most were 6 years old, data were collected yearly starting at age 10 . Parental written consent was obtained for all children involved. Participants and their classmates gave verbal assent when they were minor, and written consent after they reached 18 years of age. All instruments and procedures were approved by the University of Montreal Ethics Board.

The current study focused on two groups of participants, the 'exposed' group, who were brought to juvenile court between ages 12 and 17, and the potential control' group, who were arrested by the police during the same age period, but were never brought to court. Of the 1,037 boys from the original sample, $176(17 \%)$ had at least one juvenile court appearance and formed the 'exposed' group. They cumulated between 1 and 57 juvenile charges. Twenty of them were found not guilty or had their charges withdrawn. Among those found guilty of at least one offence, the most important sanctions were limited measures (e.g., fine, release) for 24 participants, reparatory measures (e.g., community work, donation) for 26 of them, supervisory measures (e.g., probation) for 59 of them, and open- or closedcustody placement for the remaining 47 . The 'potential control' group included 225 participants who reported having 'been arrested and taken to the police station' at least once between ages 12 and 17, but were never brought to court. Unfortunately, we had no access to police records to verify that 'potential control' group participants were in fact arrested, or whether more participants might have qualified for inclusion in this group. However, given that we used a propensity score matching approach to obtain comparable groups, we think that potential errors in self-reported arrest history would have very little effect on our final estimates. As explained in further detail below, with this approach,

${ }^{1}$ The intervention did not have a significant effect on exposure to the juvenile court. not all members of the initial 'potential control' group are included in the matched comparison group, and those who are similar to more than one 'exposed' individual are given a larger weight.

\section{Measures}

Outcomes The three adult criminality outcomes were measured from official records covering ages 18-25: (a) Having a criminal record; (b) Number of violent offences; (c) Number of nonviolent offences. Violent and nonviolent offences were examined separately because they carry different consequences for the offender and the public. Among the total 401 participants, 131 $(32.6 \%)$ had an adult criminal record. They each committed between 0 and 7 violent offences $($ mean $=0.21)$ and between 0 and 30 nonviolent offences $($ mean = 1.49), between ages 18 and 25 .

Predictors of juvenile court exposure A large number of variables measured up to age 12 and considered potential personal, familial or social risk factors for juvenile justice system intervention were tested for inclusion in the propensity score. Variables were retained if they predicted juvenile court exposure and at least one adult criminality outcome, using alpha $=.05$. Logistic and Poisson regression models were used, as appropriate. Subscales from the same instrument were assessed together in multiple regressions, and only those that uniquely predicted court exposure were retained. When measures were available at more than one data point, we retained the best predictor between the age 12 measure and the average of measures. Variables which did not meet the inclusion criteria were: father's age at birth of first child, parents' working status at intake, parental occupational prestige, parental supervision and use of punishment, maternal depression, number of children or child's rank in the family, enrolment in pre-kindergarten at age 4, kindergarten classmates' disruptive or prosocial behavior, participants' grade repetition or special class placement, verbal ability, Jesness Inventory subscales, and number of arrests before age 12 . The 14 retained variables are described below.

Personal risk factors included in the propensity score:

Self-reported delinquency. Participants were asked how often in the past 12 months $(0=$ never, $1=$ once or twice, 2 = sometimes, 3 = often), they engaged in 14 delinquent behaviors, including violent (e.g., carrying a weapon, threatening, beating someone) and nonviolent acts (e.g., arson, vandalism, theft). Cronbach's alphas were $.80, .82$, and .83 at ages 10,11 , and 12 , respectively, and scores were averaged across ages.

Self-reported antisociality. Participants filled the Jesness Inventory, a true-false personality questionnaire (Jesness, 1983). The Asocial Index, a delinquency score derived from a multiple discriminant analysis of the Jesness Inventory subscales, was averaged between ages 11 and 12 .

Self-reported alcohol/drug use. Participants reported on how often they drank alcohol, got drunk, and consumed marijuana $(0=$ never, $1=$ once or twice, $2=$ sometimes, $3=$ often). Cronbach's alphas were .54 , .58 , and .56 at ages 10,11 , and 12, respectively; scores were averaged across ages. 
Number of conduct disorder symptoms. At age 12, participants, their mother and their teacher filled their respective paper version of the Diagnostic Interview Schedule for Children. Symptoms of conduct disorder were counted if any informant reported it as present.

Child behavior. Mothers and teachers reported on the child's behavior with the Social Behavior Questionnaire, which includes disruptiveness, prosociality, antisociality, anxiety, and inattention subscales (Tremblay et al., 1991). Items were scored on a 3-point scale $(0=$ doesn't apply, $1=$ applies sometimes, $2=$ certainly applies) and subscales were averaged across ages 10, 11 and 12. Mother-rated disruptiveness (13 items covering hyperactive, aggressive, destructive, and rule-breaking behaviors; Cronbach's alphas $=.84, .83$, and .85 at ages 10,11 , and 12 , respectively) and teacher-rated antisociality (three items covering truancy, theft, and lying; Cronbach's alphas $=.44, .57$, and .50 at ages 10,11, and 12, respectively) were retained.

Physical aggression trajectory group. Three trajectories of physical aggression ('kicks, bites, hits others'; 'fights with other children'; 'bullies or intimidates others'; Cronbach's alphas ranging from .78 to .87 across data points) were previously obtained from teacher ratings at ages $6,10,11,12$, and 13 (Brame, Nagin, \& Tremblay, 2001). Participants were assigned to trajectory groups according to their highest probability of membership $(1=$ low, $51 \%$ of the original sample; $2=$ moderate, $31 \% ; 3=$ high, $18 \%$ ).

Familial risk factors included in the propensity score: Mother's age at the birth of her first child.

Parental education. In years, averaged across mothers and fathers.

Family income. Reported in 13 evenly spaced categories, in Canadian dollars, starting from $1=$ less than $\$ 5,000,2=\$ 5,000-\$ 9,999$, up to $13=\$ 60,000$, and more. Scores obtained when the participants were 10 , 11 , and 12 years old were averaged.

Parents separated/divorced when the child was 12 years old $(1=$ yes, $0=$ no)

Parental criminal record. Whether the participants' mother or father had been officially charged with an offence, as an adult ( $1=$ yes, $0=$ no).

Social risk factors included in the propensity score:

Offences committed by kindergarten classmates' fathers. The average number of official, adult offences was computed for mothers and for fathers of participants' kindergarten classmates. The classmates' fathers score was retained.

Best friend's aggression-disruptiveness. Participants and their classroom peers were asked to nominate up to four classmates who fitted a behavior description for aggression-disruptiveness $(20$ items; Cronbach's alphas $=.97$ and .96 for ages 11 and 12; Pekarik, Prinz, Liebert, Weintraub, \& Neale, 1976). Participants were also asked to name their best friend, whose peer-rated aggression-disruptiveness was computed, and averaged over the age 11 and 12 assessments.

\section{Statistical analyses}

Treatment of missing data Complete data were available for juvenile court involvement and adult criminal outcomes, but missing data affected the other variables. To avoid biases that may arise with deletion of incomplete cases or variables (Rubin, 1987), we performed multiple imputation by chained equations, using the mi ice command in Stata 11.0. Missing values were imputed 50 times using all variables considered in this study, from all available data points, with the original 1,037 participants. Analyses were run with the resulting 50 'completed' data sets and then pooled with Rubin's combination rules (Rubin, 1987), using mi estimate or programs written following Cañette \& Marchenko (Cañette \& Marchenko, 2010). All figures reported in this paper are the pooled ones (except Cronbach's alphas).

Propensity score matching The propensity score is a quantity between 0 and 1 that expresses the conditional probability for each participant to be submitted to an intervention (herein, juvenile court intervention), given a set of covariates (Rosenbaum \& Rubin, 1984). It was the prediction score obtained from a probit regression with juvenile court intervention as the binary outcome and the 14 retained predictors as covariates.

Matching was performed using the psmatch2 Stata program (Leuven \& Sianesi, 2003). The matching algorithm used, radius matching, matches each exposed individual with all unexposed individuals whose propensity score lies within a chosen distance (caliper), assigning them equal weights adding up to 1 . Unexposed individuals' weights increase if they are matched to multiple exposed individuals. Exposed individuals for whom no match is available, and potential controls who are not used in the matching, are excluded. Several calipers were tested $(.10, .05, .025, .01)$, and the one which provided the best matching quality, whereas excluding a minimal number of exposed participants, was retained. Matching quality, or the extent to which differences between exposed and unexposed groups are eliminated, is evaluated by computing standardized differences between the group means on each covariate (they should ideally be below 5\% after matching), as well as the prediction of treatment probability (Pseudo $R^{2}$; which should be close to zero after matching; Caliendo \& Kopeinig, 2008; Stuart, 2010).

Table 1 presents the effects of matching (with radius matching, caliper $=.025$ ) on balancing the covariates between groups. The propensity score matching procedure excluded 12 court-exposed participants (out of 176) for whom adequate matches could not be found.

\section{Results}

\section{Effects of juvenile court contact}

Table 2 shows the results of logistic and Poisson regression models comparing exposed and unexposed participants on the three adult criminality outcomes. After propensity score matching, court-processed participants remained at significantly higher risk of being convicted of an adult criminal offence, and committed significantly more violent and nonviolent offences, than their peers. The risk of having an adult criminal record was $50.0 \%$ for exposed individuals and $24.3 \%$ for their matched peers. The mean number of violent and nonviolent adult offences for each group is presented in Figure 1. 
Table 1 Standardized differences between exposed and unexposed groups on predictors of juvenile court involvement, before and after propensity score matching

\begin{tabular}{lcr}
\hline & \multicolumn{2}{c}{$\begin{array}{c}\text { Standardized bias between exposed and unexposed } \\
\text { groups (\%) }\end{array}$} \\
\cline { 2 - 3 } Predictor of juvenile court involvement & Before matching & After matching \\
\hline Self-reported delinquency age 10-12 & 29.8 & 9.3 \\
Self-reported Antisocial Index age 11-12 & 31.0 & 1.0 \\
Self-reported alcohol/drug use age 10-12 & 36.5 & 3.2 \\
Number of CD symptoms age 12 & 35.0 & -1.9 \\
Mother-reported disruptiveness age 10-12 & 48.3 & 10.6 \\
Teacher-reported antisociality age 10-12 & 57.6 & -0.7 \\
Physical aggression trajectory group & 40.6 & 0.0 \\
Mother's age at birth of first child & -25.5 & -13.8 \\
Parental education & -27.0 & -0.6 \\
Family income age 10-12 & -30.5 & 2.3 \\
Parents separated/divorced age 12 & 34.8 & -4.0 \\
Mother or father accused of an offence before 1990 & 31.5 & -0.7 \\
Offences committed by K classmates' fathers & 32.2 & -4.7 \\
Best friends' aggression-disruptiveness age $11-12$ & 35.6 & -2.5 \\
Average bias (absolute values) & 35.4 & 4.0 \\
Prediction of court involvement (Pseudo- $R^{2}$ ) & .15 & .01 \\
\hline
\end{tabular}

Standardized bias $=($ Mean score for exposed youths - Mean score for unexposed youths $) /$ Pooled standard deviation.

Table 2 Effects of juvenile court involvement on three adult criminality outcomes, before and after propensity score matching

\begin{tabular}{lccc}
\hline & \multicolumn{2}{c}{ Official adult criminality outcomes, up to age 25} \\
\cline { 2 - 4 } & $\begin{array}{c}\text { Risk of adult } \\
\text { criminal record (OR) }\end{array}$ & $\begin{array}{c}\text { Number of violent } \\
\text { adult offences (IRR) }\end{array}$ & $\begin{array}{c}\text { Number of nonviolent } \\
\text { adult offences (IRR) }\end{array}$ \\
\hline $\begin{array}{c}\text { Before matching }(N=176 \text { exposed; } \\
225 \text { unexposed) }\end{array}$ & $5.24^{* * *}(3.30-8.33)$ & $6.07^{* * *}(3.44-10.69)$ & $4.21^{* * *}(3.46-5.13)$ \\
$\begin{array}{c}\text { After matching }(N=164 \text { exposed; } \\
218 \text { matched peers) }\end{array}$ & $3.13^{* * *}(1.80-5.44)$ & $2.60^{* *}(1.39-4.87)$ & $1.87^{* *}(1.19-2.93)$ \\
\hline
\end{tabular}

OR, odds ratio; IRR, incidence-rate ratio.

$95 \%$ confidence intervals in parentheses.

${ }^{* *} p<.005 ;{ }^{* * *} p<.001$.

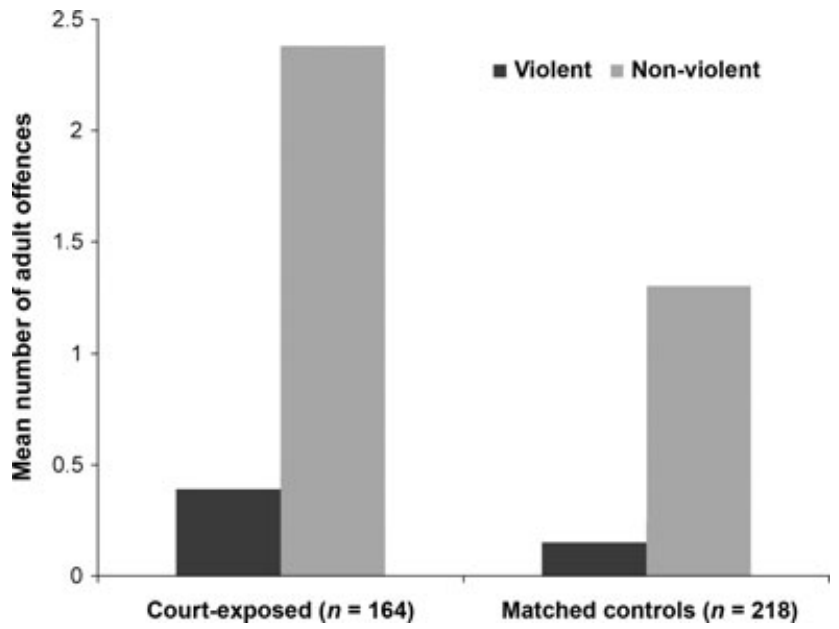

Figure 1 Mean number of violent and nonviolent adult offences, from ages $18-25$ years, for individuals exposed to juvenile court and their matched counterparts

\section{Sensitivity analyses}

We tested the sensitivity of our results to alternative model specifications. The estimates of the impact of court exposure on the three adult criminal outcomes are presented in Table 3, with the original estimates (from Table 2) in panel A.

First, we assessed the impact of our decision to impute missing data on the juvenile arrest variable. As presented in the Method section, only individuals who reported having been arrested between the ages of 12 and 17 were included as 'potential controls' for individuals who were sent to court. Information on juvenile arrest was missing for 68 of the 1,037 participants. As with other variables used in the study, missing values on the juvenile arrest variable were imputed 50 times with multiple imputation by chained equations, using all variables considered in this study, from all available data points, with the original 1,037 participants. To test whether imputation of the juvenile arrest variable had an impact on our results, we reran the analyses after excluding participants with missing data on juvenile arrest. The results, presented in Panel B of Table 3, are very close to the original results.

Second, we examined how alternative matching algorithms, or different calipers, would influence the estimates. Panels $\mathrm{C}$ through $\mathrm{F}$ of Table 3 present the 
Table 3 Effects of juvenile court involvement on three adult criminality outcomes, with alternative model specifications

\begin{tabular}{|c|c|c|c|c|}
\hline & \multicolumn{4}{|c|}{ Official adult criminality outcomes, up to age 25} \\
\hline & $\begin{array}{c}\text { Sample size (range } \\
\text { across the } 50 \text { imputed } \\
\text { samples) }\end{array}$ & $\begin{array}{l}\text { Risk of adult } \\
\text { criminal } \\
\text { record }(\mathrm{OR})\end{array}$ & $\begin{array}{l}\text { Number of violent } \\
\text { adult offences (IRR) }\end{array}$ & $\begin{array}{c}\text { Number of } \\
\text { nonviolent adult } \\
\text { offences (IRR) }\end{array}$ \\
\hline $\begin{array}{l}\text { A. Original results (radius matching, } \\
\text { caliper }=.025 \text { ) }\end{array}$ & 359-396 & $3.13^{* * *}(1.80-5.44)$ & $2.60^{* *}(1.39-4.87)$ & $1.87^{* *}(1.19-2.93)$ \\
\hline B. No imputation on arrest & $340-365$ & $2.81^{* * *}(1.60-4.95)$ & $2.50 * *(1.33-4.71)$ & $1.87^{* *}(1.21-2.88)$ \\
\hline C. Radius matching, caliper $=.01$ & $342-377$ & $3.11^{* * *}(1.75-5.54)$ & $2.72^{* *}(1.31-5.64)$ & $2.03^{* *}(1.25-3.29)$ \\
\hline D. Radius matching, caliper $=.10$ & $386-412$ & $3.34 * * *(1.98-5.63)$ & $2.61 * *(1.49-4.57)$ & $1.96^{* * *}(1.37-2.81)$ \\
\hline E. NN matching, $k=2$, caliper $=.025$ & $281-314$ & $3.25^{* * *}(1.78-5.93)$ & $2.74 * *(1.33-5.66)$ & $1.93 *(1.13-3.30)$ \\
\hline $\begin{array}{l}\text { F. NN matching, } k=1 \text {, caliper }=.025 \text {, } \\
\text { no replacement }\end{array}$ & $230-266$ & $3.29 * * *(1.74-6.21)$ & $3.57^{* * *}(1.78-7.17)$ & $2.32^{* * *}(1.67-3.24)$ \\
\hline G. Controlling for pre-offence delinquency & 230-266 & $3.30 * * *(1.75-6.25)$ & $3.57^{* * *}(1.78-7.17)$ & $2.31^{* * *}(1.66-3.20)$ \\
\hline H. Controlling for covariates with $>5 \%$ bias & 359-396 & $3.06^{* * *}(1.73-5.42)$ & $2.45^{* *}(1.29-4.65)$ & $1.66^{*}(1.05-2.60)$ \\
\hline
\end{tabular}

OR, odds ratio; IRR, incidence-rate ratio.

$95 \%$ confidence intervals in parentheses.

${ }^{*} p<.05,{ }^{* *} p<.01,{ }^{* * *} p<.001$

results obtained with a more or less stringent caliper, and with nearest-neighbor (NN) matching, using $k=2$ or $k=1$ nearest neighbors. Again, the results are similar.

Third, we used a more stringent control of delinquency prior to court exposure by controlling for selfreported delinquency the year preceding the offence. For exposed individuals, preoffence delinquency was simply the self-reported delinquency score obtained at the last data collection preceding the date of the first offence. For matched, nonexposed individuals, preoffence delinquency was the self-reported delinquency score obtained at the last data collection preceding the date of the matched exposed individual's first offence. We ensured that unique nonexposed individuals would be matched to each exposed individual (within a caliper $=.025$ ), using a NN matching algorithm, with $k=1$ nearest neighbor, and no replacement (same as in Panel F). When preoffence delinquency was entered as a predictor in the logistic and Poisson regression models, the coefficients for the effects of court exposure remained essentially unchanged (compare Panel G to Panel F).

Finally, we tested whether our results were influenced by the remaining bias between exposed and nonexposed individuals on certain variables. Of the variables included in the propensity score, three had a standardized bias above 5\% after matching: Self-reported delinquency at ages 10-12; Motherreported disruptiveness at ages 10-12; Mother's age at birth of first child (see Table 1). To increase statistical control for these variables, we included all three as covariates in the logistic and Poisson regression models. The coefficients for the effects of court exposure decreased only slightly (see Panel $\mathrm{H}$ ).

\section{Discussion}

This study showed that male adolescents processed in juvenile court, under the Canadian Young
Offenders Act, had three times the odds of being convicted of an adult criminal offence by age 25 , and committed close to twice as many violent and nonviolent adult offences, compared with matched peers who were arrested by the police, but not sent to court.

These results suggest that formal processing in juvenile court may place adolescents on a more criminal path than the one they might follow if released or diverted. They add to a growing body of research conducted in diverse juvenile justice systems, which placed different levels of emphasis on young offenders' needs vs. the nature of their offence, and used various rates of diversion vs. official court processing. Across this variety of juvenile justice systems, the results indicate that increased judicial contact has no deterrent or rehabilitative effect on young offenders and may actually increase reoffending (Farrington, 1977; Huizinga et al., 2004; McAra \& McVie, 2007; Petrosino et al., 2010). Among the possible mechanisms, processing juveniles through court may lead to reduced prosocial opportunities and other labeling effects (Sampson \& Laub, 1997). For youths submitted to custodial placements, increased contact with deviant peers may heighten risk for deviancy training (Dishion, McCord, \& Poulin, 1999; Shapiro, Smith, Malone, \& Collaro, 2010). Future research is needed to understand how the juvenile justice system may be having criminogenic effects.

Despite this study's rich assessment of participants' behavior and environments, it remains possible that an unmeasured factor may have influenced both juvenile court exposure and adult criminality, independently of the propensity score. For instance, we had no information on the grounds for arrest in participants not sent to court, or on the specific reasons that may have influenced the decision to press charges or not. To the extent that such unmeasured factors were not accounted for by the propensity score, there may be an under-adjustment 
bias. Nevertheless, the consistency of our results with those of randomized studies (Petrosino et al., 2010) increases our confidence in their validity.

A potential limitation to the generalizability of our results is the exclusion of some court-exposed individuals when applying propensity score matching. However, only a small number of court-processed individuals were excluded (less than 7\%). Further, the multiple imputation procedure, by providing slightly different matches in each imputation, excluded different subsets of exposed individuals, thus reducing potential bias.

\section{Conclusion}

This study is the first propensity score matching evaluation of the juvenile justice system's effects into adulthood. It contributes to knowledge about the overall effectiveness of juvenile court interventions as they are implemented in 'real world' conditions (Mears, Cochran, Greenman, Bhati, \& Greenwald, 2011). Our results indicate that they fail to prevent adult criminal involvement and may instead increase the likelihood of violent and nonviolent crimes, thus increasing suffering, and raising justice, health, and social costs (Cohen \& Piquero, 2009). Along with previous studies of other juvenile justice systems, this study highlights a pressing need to gather more research evidence on effective interventions to prevent juvenile delinquency (Boisjoli, Vitaro, Lacourse, Barker, \& Tremblay, 2007; Schweinhart et al., 2005) and to reduce recidivism among youth who commit crime (Drake, Aos, \& Miller, 2009; MacDonald \& Turner, 2007). It is crucial that such knowledge then be shared to help shape more effective crime policy (Welsh \& Farrington, 2012).

\section{Acknowledgements}

This study was funded by Canada's CIHR and SSHRC research funding agencies as well as Québec's FQRSC and FRSQ funding agencies. This study was completed while the first author was at the Geary Institute, University College Dublin, Ireland, and supported by a postdoctoral fellowship from Québec's FQRSC. We thank Charles-Edouard Giguère, Hélène Beaumont, and Qian Xu (all from the Research Unit on Children's Psychosocial Maladjustment, Universite de Montreal, Canada) for data management and preparation. The authors declare they have no financial relationships relevant to this article to disclose.

\section{Correspondence}

Amélie Petitclerc, Teachers College, Columbia University, 525 West 120th Street, Box 39, New York, NY 10027, USA; Email: amelie.petitclerc@tc.columbia.edu

\section{Key points}

- Previous studies show that involvement in the juvenile justice system either has no effect or increases criminal behavior in the next year.

- This study is the first to investigate the effects of juvenile court exposure over a long period, up to age 25 , with a propensity score matching method.

- Results show that court-processed male adolescents were more likely to have an adult criminal record, and committed more violent and nonviolent offences than their matched peers who were arrested, but not sent to juvenile court.

- The results call into question the effectiveness of the juvenile justice system's interventions. We suggest that they should be revised to include interventions that have been empirically supported to reduce recidivism.

\section{References}

Blokland, A.A.J., Nagin, D.S., \& Nieuwbeerta, P. (2005). Life span offending trajectories of a Dutch conviction cohort. Criminology, 43, 919-954.

Boisjoli, R., Vitaro, F., Lacourse, É., Barker, E.D., \& Tremblay, R.E. (2007). Impact and clinical significance of a preventive intervention for disruptive boys: 15 year follow-up. British Journal of Psychiatry, 191, 415-419.

Brame, B., Nagin, D.S., \& Tremblay, R.E. (2001). Developmental trajectories of physical aggression from school entry to late adolescence. Journal of Child Psychology and Psychiatry, 42, 503-512.

Caliendo, M., \& Kopeinig, S. (2008). Some practical guidance for the implementation of propensity score matching. Journal of Economic Surveys, 22, 31-72.

Cañette, I., \& Marchenko, Y. (2010). Combining results other than coefficients in e(b) with multiply imputed data. Stata
Corp. Frequently Asked Questions, from http://www. stata.com/support/faqs/statistics/combine-results-withmultiply-imputed-data/ [last accessed 2011 July].

Cohen, M.A., \& Piquero, A.R. (2009). New evidence on the monetary value of saving a high risk youth. Journal of Quantitative Criminology, 25, 25-49.

DeLisi, M., \& Piquero, A.R. (2011). New frontiers in criminal careers research, 2000-2011: A state-of-the-art review. Journal of Criminal Justice, 39, 289-301.

Dishion, T.J., McCord, J., \& Poulin, F. (1999). When interventions harm: Peer groups and problem behaviors. American Psychologist, 54, 755-764.

Drake, E.K., Aos, S., \& Miller, M.G. (2009). Evidence-based public policy options to reduce crime and criminal justice costs: Implications in Washington State. Victims \& Offenders, 4, 170-196.

Farrington, D.P. (1977). The effects of public labelling. British Journal of Criminology, 17, 112-125. 
Farrington, D.P. (1987). Epidemiology. In H.C. Quay (Ed.), Handbook of juvenile delinquency (pp. 33-61). New York: John Wiley \& Sons.

Gatti, U., Tremblay, R.E., \& Vitaro, F. (2009). Iatrogenic effects of juvenile justice. Journal of Child Psychology and Psychiatry, 50, 991-998.

Hirschi, T., \& Gottfredson, M. (1983). Age and the explanation of crime. The American Journal of Sociology, 89, 552-584.

Huizinga, D., Schumann, K., Ehret, B., \& Elliott, A. (2004). The effects of juvenile justice system processing on subsequent delinquent and criminal behavior: A cross-national study. Report to the National Institute of Justice. Document number 205001, from www.ncjrs.gov/pdffiles1/nij/grants/205001. pdf [last accessed 2012 September]: Bremen, Germany and Boulder, CO.

Jesness, C.F. (1983). The Jesness Inventory (rev. ed.). Palo Alto, CA: Consulting Psychologists Press.

Leuven, E., \& Sianesi, B. (2003). PSMATCH2: Stata module to perform full Mahalanobis and propensity score matching, common support graphing, and covariate imbalance testing, Available from: http://ideas.repec.org/c/boc/bocode/ s432001.html [last accessed 4 April 2010].

MacDonald, G.M., \& Turner, W. (2007). Treatment foster care for improving outcomes in children and young people. Campbell Systematic Reviews, 9, 95 pp.

McAra, L., \& McVie, S. (2007). Youth justice? The impact of system contact on patterns of desistance from offending. European Journal of Criminology, 4, 315-345.

Mears, D.P., Cochran, J.C., Greenman, S.J., Bhati, A.S., \& Greenwald, M.A. (2011). Evidence on the effectiveness of juvenile court sanctions. Journal of Criminal Justice, 39, 509-520.

Miller, T.R., Cohen, M.A., \& Wiersema, B. (1996). Victim costs and consequences: A new look. Washington, DC: National Institute of Justice.

Pekarik, E.G., Prinz, R.J., Liebert, D.E., Weintraub, S., \& Neale, J.M. (1976). The Pupil Evaluation Inventory: A sociometric technique for assessing children's social behavior. Journal of Abnormal Child Psychology, 4, 83-97.

Petrosino, A., Turpin-Petrosino, C., \& Guckenburg, S. (2010). Formal system processing of juveniles: Effects on delinquency. Campbell Systematic Reviews, 1, 88 pp.
Rosenbaum, P., \& Rubin, D. (1984). Reducing bias in observational studies using subclassification on the propensity score. Journal of the American Statistical Association, 79, 516-524.

Rubin, D.B. (1987). Multiple imputation for nonresponse in surveys. New York: J. Wiley \& Sons.

Sampson, R.J., \& Laub, J.H. (1997). A life-course theory of cumulative disadvantage and the stability of delinquency. in T.P. Thornberry (Ed.), Developmental theories of crime and delinquency: Advances in criminological theory (Vol. 7, pp. 133-161). New Brunswick, NJ: Transaction.

Sampson, R.J., \& Laub, J.H. (2003). Life-course desisters? Trajectories of crime among delinquent boys followed to age 70. Criminology, 41, 555-592.

Schweinhart, L., Montie, J., Xiang, Z., Barnett, W.S., Belfield, C.R., \& Nores, M. (2005). Lifetime effects: The high/scope Perry preschool study through age 40 (Vol. 14). Ypsilanti, MI: High/ Scope Press.

Shapiro, C.J., Smith, B.H., Malone, P.S., \& Collaro, A.L. (2010). Natural experiment in deviant Peer exposure and youth recidivism. Journal of Clinical Child and Adolescent Psychology, 39, 242-251.

Stuart, E.A. (2010). Matching methods for causal inference: A review and a look forward. Statistical Science, 25, 1-21.

Tremblay, R.E., Loeber, R., Gagnon, C., Charlebois, P., Larivée, S., \& LeBlanc, M. (1991). Disruptive boys with stable and unstable high fighting behavior patterns during junior elementary school. Journal of Abnormal Child Psychology, 19, 285-300.

Welsh, B.C., \& Farrington, D.P. (2012). Science, politics, and crime prevention: Toward a new crime policy. Journal of Criminal Justice, 40, 128-133.

Wiesner, M., Capaldi, D.M., \& Kim, H.K. (2007). Arrest trajectories across a 17 -year span for young men: Relation to dual taxonomies and self-reported offense trajectories. Criminology, 47, 835-863.

Accepted for publication: 9 January 2012

Published online: 26 September 2012 